\title{
Degradation rate of mitochondrial proteins in Arabidopsis thaliana cells
}

\author{
Clark J. Nelson, Lei Li, Richard Jacoby, A. Harvey Millar* \\ ARC Centre of Excellence in Plant Energy Biology \& Centre for Comparative Analysis of \\ Biomolecular Networks, M316, The University of Western Australia, 35 Stirling Highway, \\ Crawley WA 6009 Australia.
}

Running title: Plant organellar protein turnover

*Corresponding author: A. Harvey Millar

ARC Centre of Excellence in Plant Energy Biology

4th Floor MCS Building M316

University of Western Australia

35 Stirling Highway

Crawley 6009 WA, Australia

Tel: +61 864887245

Fax: +61 864884401

e-mail: harvey.millar@uwa.edu.au 


\begin{abstract}
The turnover of the proteomes of organelles in plant cells are known to be governed by both whole cell and organelle-specific processes. However, the rate and specificity of this protein turnover has not been explored in depth to understand how it affects different organellar processes. Here we have used progressive ${ }^{15} \mathrm{~N}$ labeling of Arabidopsis cells, and focused on the turnover rate of proteins in mitochondria. We provide estimates of degradation rate $\left(\mathrm{K}_{\mathrm{d}}\right)$ for 224 mitochondrial proteins, showing a range of over 50 -fold in $\mathrm{K}_{\mathrm{d}}$. Protein complexes, most notably the respiratory chain complexes had $\mathrm{K}_{\mathrm{d}}$ values that were generally coordinated and we have interpreted these measurements to outline how protein $\mathrm{K}_{\mathrm{d}}$ differs within protein complexes and between functional categories. The fastest turnover rates were reported for DNA/RNA metabolism enzymes, chaperones, and proteases.
\end{abstract}


Introduction

Proteomics has matured to the point where it is considered a high-throughput systems biology technique, approaching the robustness, but still lacking the depth, of transcript profiling. As a result of the dramatic increase in sensitivity and resolution of mass spectrometry (MS) instrumentation, modern proteomics can now identify thousands of proteins from a sample in a matter of hours ${ }^{1}$. In addition to mere identification, quantitation of proteins has also become routine using gel-based methods, stable-isotope labeling techniques, as well as label-free methods ${ }^{1}$. While such measurements have proven useful in helping to understand biological phenomena, abundance values by themselves do not provide insight into the underlying mechanisms that determine these values. Protein synthesis and protein degradation are the competing processes that determine a polypeptide's abundance. Protein synthesis is typically thought to be independent of protein abundance, but rather correlates with transcript occupancy on ribosomes, most likely in a linear manner. In contrast, protein degradation is believed to be a function of protein abundance and is an exponential process ${ }^{2}$. The rate of protein degradation will also vary depending on the catalytic rate of the proteolysis machinery at a given location within the cell.

Early studies of protein turnover typically involved radiolabeling of proteins, a slow and tedious process that only yielded estimates for total protein turnover or degradation rates for just a few proteins ${ }^{2,3}$. Given the advent of several new technologies, including MS, researchers have begun to produce high-volume datasets that report turnover rates on a proteome scale. Different techniques have proven effective in high volume studies, with some of the more frequently used methods including fluorescent tagging in conjunction with flow cytometry, TAP-tagging and mass westerns in combination with application of cycloheximide, and stable-isotope $\left({ }^{13} \mathrm{C},{ }^{15} \mathrm{~N},{ }^{2} \mathrm{H},{ }^{18} \mathrm{O}\right)$ labeling with analysis by $\mathrm{MS}{ }^{3}$. 
Arguably, the stable-isotope/MS approach has become the most popular in recent years and offers several benefits. Such benefits include sensitivity, parallel measurement of many proteins, minimal system perturbation, simultaneous measurement of synthesis and degradation, and measurements for proteins that are natively folded and in the appropriate subcellular localization ${ }^{3}$.

The first study that used stable isotopes and MS to measure protein degradation rates $\left(\mathrm{K}_{\mathrm{d}}\right)$ in a highly parallel fashion occurred more than a decade ago in an auxotrophic yeast line grown in a chemostat with isotopically-labeled leucine ${ }^{4}$. Similar approaches have since been used to measure $\mathrm{K}_{\mathrm{d}}$ in bacteria, cell culture, and even whole organisms ${ }^{5-9}$. The counterpart to $\mathrm{K}_{\mathrm{d}}$ is protein synthesis rate $\left(\mathrm{K}_{\mathrm{s}}\right)$, which some studies have reported as well ${ }^{8,9}$. In plants, there are a few studies that have assessed protein turnover. In one report, deuterium oxide was used to rapidly label proteins in Arabidopsis seedlings and study cullin-associated and neddylaton dissociation (CAND1) and transport inhibitor response 1 (TIR1), proteins involved in auxin metabolism ${ }^{10}$. However, deuterium at high levels is toxic for organisms ${ }^{11}$ and deuterium-induced perturbation to cellular homeostasis was evident by altered transcript profiles in the aforementioned study, making this a suboptimal labeling strategy ${ }^{10}$. Alternatively, the heavy isotope of nitrogen, ${ }^{15} \mathrm{~N}$, has been used in several proteomic studies and had no observable differences in growth or protein expression between plants grown with ${ }^{14} \mathrm{~N}$ or ${ }^{15} \mathrm{~N}$ isotopes ${ }^{12-14}$. We have previously used this stable isotope to measure $\mathrm{K}_{\mathrm{d}}$ and $\mathrm{K}_{\mathrm{s}}$ in 84 proteins in Arabidopsis cell culture using a 2DE MALDI TOF/TOF workflow ${ }^{14}$.

When considering a protein's abundance and the processes that determine it, multiple layers of biological complexity must be considered. Such complexity includes but is not limited to subcellular localization and tissue type. Various studies have reported that organellar proteins tend to have different turnover rates compared to cytosolic proteins $5,14,15$. In mice, mitochondrial proteins had $\mathrm{K}_{\mathrm{d}}$ values that were generally slower and occupied a 
much narrower range than those observed for cytosolic proteins ${ }^{5}$. A recent study which assessed $K_{d}$ values from several subcellular fractions in human cell culture, reported that proteins with multiple subcellular localizations often turned over at different rates in the different compartments ${ }^{16}$. Tissue type also has a significant effect on protein turnover. In mice, the proteome as a whole turned over more quickly in the blood and liver as compared to brain tissues ${ }^{5}$. This pattern was consistent with mitochondrial proteins from mouse liver turning over more rapidly than those same proteins from the heart ${ }^{15}$

An additional layer of complexity to consider in protein turnover involves proteinprotein interactions, particularly the formation of protein complexes. Components of protein complexes often have similar rates of turnover ${ }^{5,17}$. Different studies have shown that ribosomal proteins and cytoskeletal complexes possessed slow turnover rates, while proteasome components turned over more rapidly ${ }^{5,17}$. In contrast, a measurement of mitochondrial protein complexes in multiple tissues of mice reported little coordination of the respiratory chain complexes although all of the turnover rates for respiratory components varied over a narrow range ${ }^{15}$. In a detailed study in Arabidopsis cell culture of complex V (ATP synthase) subunits using ${ }^{15} \mathrm{~N}$ labeling in conjunction with blue native (BN) PAGE and MS, we have shown that subunits exhibited diverse $\mathrm{K}_{\mathrm{d}}$ values depending on whether they were constituents of subcomplexes or the holocomplex. These data were used to propose a model for complex $\mathrm{V}$ assembly ${ }^{18}$. For complex I of OXPHOS and its subcomplexes, a similar approach was used to refine an assembly model for complex I and relate this to an evolutionary model for complex I assembly ${ }^{19}$.

In this study, we have modified our methods and conducted an LC-MS/MS analysis of organellar proteins from Arabidopsis cell culture in order to provide greater insight into 
compartment specific processes. We provide estimates of turnover rates for several hundred mitochondrial proteins. We report that different mitochondrial proteins turn over at widely divergent rates, with our data showing over 50-fold variation in degradation rates between proteins. A comparison of our data with turnover rates reported from a murine study revealed that both mitochondrial proteomes displayed similar turnover kinetics. Mitochondrial protein complexes, including the respiratory chain complexes, had turnover rates that were generally coordinated and we interpret these measurements to outline how protein $\mathrm{K}_{\mathrm{d}}$ differs within protein complexes and between functional categories.

\section{Materials and Methods}

\section{Culture growth, isotopic labeling and organelle isolation}

Arabidopsis cell culture was grown as previously described ${ }^{14}$. Briefly, cells were grown in modified Murashige and Skoog medium (no vitamins, 3\% (w/v) sucrose, $0.5 \mathrm{mg} / \mathrm{L}$ naphthalene acetic acid, $0.05 \mathrm{mg} / \mathrm{L}$ kinetin $(\mathrm{pH} 5.8))$ at $22{ }^{\circ} \mathrm{C}$ under continuous light (90 $\mu \mathrm{mol} \mathrm{m} \mathrm{m}^{-2} \mathrm{~s}^{-1}$ ) with orbital shaking at $120 \mathrm{rpm}$. Cultures were grown in $250 \mathrm{~mL}$ Erlenmeyer flasks by passaging $20 \mathrm{~mL}$ of 7-day-old cells into $100 \mathrm{~mL}$ of new media. To begin the labeling experiment, 7-day old cells were sub-cultured into media containing nitrogen salts that were ${ }^{15} \mathrm{~N}$-labeled, ${ }^{15} \mathrm{NH}_{4}{ }^{15} \mathrm{NO}_{3}(1.65 \mathrm{~g} / \mathrm{L})$ and ${ }^{15} \mathrm{KNO}_{3}(1.9 \mathrm{~g} / \mathrm{L})$. Samples were then collected at 1, 4, 5, and 7 days and mitochondrial enrichments conducted as described previously ${ }^{18}$. Following organelle isolation, samples were aliquoted and flash frozen in liquid nitrogen. In order to calculate the dilution effect due to growth $\left(\mathrm{K}_{\text {dilution }}\right)$, from 3 independent samples at each time point, total protein was extracted from $5 \mathrm{~mL}$ of cell culture using a chloroform/methanol method ${ }^{20}$. The pellets were then dissolved in lysis buffer ( $8 \mathrm{M}$ urea, 40 
$\mathrm{mM}$ Tris base, 4\% (w/v) CHAPS) and protein concentrations determined by an Amido Black method ${ }^{21}$. These values were used to calculate total protein at each time point and the relative growth rate $\left(\mathrm{d}^{-1}\right)$ determined by regression analysis of these data.

\section{Protein separation and digestion}

For separation of proteins, $50 \mu \mathrm{g}$ of protein for each sample was loaded into three adjacent lanes of a Criterion 5-15\% precast gradient gels (Biorad) and separated electrophoretically for approximately fifty minutes at $200 \mathrm{~V}$. Gels were rinsed two times in $\mathrm{ddH}_{2} \mathrm{O}$ and then stained overnight with colloidal Coomassie Brilliant Blue G250 and then destained the next morning several times using $\mathrm{ddH}_{2} \mathrm{O}$. Gel lanes were then cut into eight fractions with approximately equal Coomasie staining in each fraction and sliced further into 1-2 $\mathrm{mm}$ pieces and placed into microfuge tubes. Samples were processed as described previously ${ }^{12}$, with fractions destained two more times with $50 \% \mathrm{MeOH}, 100 \mathrm{mM} \mathrm{NH}_{4} \mathrm{HCO}_{3}$. Sliced gel bands were then dehydrated for 2 minutes in $50 \%(\mathrm{v} / \mathrm{v})$ acetonitrile, $25 \mathrm{mM}$ $\mathrm{NH}_{4} \mathrm{HCO}_{3}$ and 30 seconds in acetonitrile before drying in a rotary evaporator for 15 minutes. Dried gel pieces were resuspended in $25 \mathrm{mM}$ DTT incubated for 30 minutes at $55{ }^{\circ} \mathrm{C}$ in 25 mM DTT, $25 \mathrm{mM} \mathrm{NH} \mathrm{HCO}_{3}$. Samples were then cooled to room temperature and $55 \mathrm{mM}$ iodacetamide, $25 \mathrm{mM} \mathrm{NH}_{4} \mathrm{HCO}_{3}$ added and allowed to stand in the dark for 30 minutes. Excess solvent was removed and gel pieces rinsed with $\mathrm{ddH}_{2} \mathrm{O}$ and then dehydrated again as described above. Samples were then proteolyzed by resuspending gel fragments in $5 \mathrm{ng} / \mu \mathrm{L}$ trypsin (Promega), $25 \mathrm{mM} \mathrm{NH} \mathrm{HCO}_{3}, 3 \%(\mathrm{v} / \mathrm{v})$ acetonitrile. After overnight digestion, samples were extracted with $1 \mathrm{~mL}$ of $1 \%(\mathrm{v} / \mathrm{v})$ TFA followed by another extraction with (70/25/5) acetonitrile/water/TFA and the two extractions combined. Peptides were then dried in a rotary evaporator and stored at $-20^{\circ} \mathrm{C}$ until LC-MS/MS analysis. 


\section{LC-MS/MS}

Samples were resuspended in 5\% (v/v) acetonitrile, $0.1 \%$ formic acid (v/v), and the equivalent of $4 \mu \mathrm{g}$ of tryptic digest was loaded onto a C18 high capacity nano LC chip (Agilent) in 95\% Buffer A $(0.1 \%(\mathrm{v} / \mathrm{v})$ formic acid in Optima grade water (Fisher)) and 5\% Buffer B (0.1\% formic acid in Optima grade acetonitrile (Fisher)) using an 1100 series capillary pump (Agilent). Following loading, samples were eluted from the C18 column and into an inline 6510 Series QTOF mass spectrometer (Agilent) with an 1100 series nano pump (Agilent) using the following gradient: $5 \% \mathrm{~B}$ to $45 \% \mathrm{~B}$ in 26 minutes, $45 \%$ to $60 \% \mathrm{~B}$ in 3 minutes, $60 \%$ to $100 \% \mathrm{~B}$ in 1 minute. Fractions from a given sample were analyzed in order and a blank was run between samples. The QTOF was operated in a data-dependent fashion with an MS spectrum collected prior to the three most abundant ions subjected to tandem mass spectrometry from doubly, triply, and higher charge states. Ions were dynamically excluded for 0.4 minutes following fragmentation. MS data were collected at four spectra per second while MS/MS spectra were collected at two spectra per second.

\section{Data analysis}

Agilent .d files were converted to centroided mzData files and the Mascot search algorithm v.2.3 (Matrix Science) used to search tandem mass spectra against proteins from the TAIR 10 release of Arabidopsis (www.arabidopsis.org), which contains 35,386 sequences. Search parameters included: trypsin as enzyme, one missed cleavage allowed, $100 \mathrm{ppm}$ mass tolerance for parent ion, $0.5 \mathrm{Da}$ tolerance on MS/MS peaks, fixed carabamidomethylation of cysteine, variable oxidation of methionine, and potential ${ }^{15} \mathrm{~N}$ 
metabolic labeling. For determination of peptide and protein probabilities, Mascot results were exported as .dat files, which were then converted to pep.xml using the ToPepXML tool in the Transproteomic pipeline v. 4.6 (TPP). Pep.xml files were then analyzed using the PeptideProphet from the TPP with the accurate mass binning option selected. These results were then assembled using the ProteinProphet tool, also within the TPP. For protein identification, we required at least two high-quality peptides (TPP peptide probability $\geq 0.9$ ) giving a protein probability of $\geq 0.99$. In addition, for a small subset of 8 proteins we were only able to make identifications based on 1 peptide and we required this peptide to have a TPP peptide probability $\geq 0.95$.

For quantitation, results were exported from Mascot as xml files and the results parsed using in-house scripts written in Mathematica (Wolfram Research). As another filter, in addition to the TPP peptide probability $\geq 0.9$ cut-off, we removed lower abundance peptides that had Mascot ion scores below 20 to reduce unreliable measurements. This approach, to increase stringency when combining peptide data to measure ${ }^{15} \mathrm{~N}$ incorporation for proteins, was modified from earlier work ${ }^{14}$. Using the XCMS library which runs in the statistical package $\mathrm{R}$, an extracted ion chromatogram (EIC) was generated $\pm 50 \mathrm{ppm}$ on the monoisotopic mass for all observed peptides. For a given peptide, the elution time is defined by picking a chromatographic peak for the monoisotopic EIC data ${ }^{22}$ and all MS scans within one standard deviation of the EIC peak center were averaged using XCMS and exported as a tsv file. These data were then parsed with Mathematica and exported as a tab separated text file that was then analyzed by the Isodist program ${ }^{23}$ to determine ${ }^{15} \mathrm{~N}$ labeling. Settings for Isodist were the same as previously reported ${ }^{14}$, with five rounds of fitting conducted in order to find the abundance (amplitude) of the natural abundance (NA) peptides and the heavy labeled peptides $(\mathrm{H}),{ }^{15} \mathrm{~N}$ incorporation level, spectral peak width, mass error, and noise. To ascertain the quality of the fit, spectra were filtered by taking the ratio of the Chi-squared 
value divided by the total amplitude of NA and $\mathrm{H}$ peptides. For 1 day samples, spectra with a ratio less than $2 \times 10^{8}$ were considered while a threshold of $8 \times 10^{8}$ was used for all other time points.

In order to calculate protein $\mathrm{K}_{\mathrm{d}}$ values, only peptides unique to a locus in the genome and were considered. For all measurements, the relative isotope abundance (RIA) for the natural abundance was calculated (equation 1). For all measurements of a given peptide in a sample at a given time point, the median RIA value was used and then for each protein the median RIA value of all measured peptides was used to represent the sample at that time point. Then for a given protein at a given time point, the RIA was averaged across all observed samples. The RIA was taken as one at $\mathrm{T}_{0}$ and then with RIA values of all observed time points was used to calculate a $\mathrm{K}_{\mathrm{loss}}$ via linear regression using equation 2 . Only proteins with an $\mathrm{R}^{2} \geq 0.85$ are presented. For proteins observed at only one time point, at least two observations (two peptides or the same peptide in two samples) were required and all data were manually inspected; for these proteins $\mathrm{K}_{\text {loss }}$ is an average degradation rate between $\mathrm{T}_{0}$ and the observed time point. Because the decrease in relative abundance of NA peptides over time is due to protein degradation as well as dilution due to growth, The protein degradation rate $\left(\mathrm{K}_{\mathrm{d}}\right)$ is the difference between $\mathrm{K}_{\text {loss }}$ and $\mathrm{K}_{\text {dilution }}$ as shown in equation $3 . \mathrm{K}_{\text {dilution }}$ was 0.168 $\mathrm{d}^{-1}$ for our cell culture.
1) $\quad \mathrm{RIA}=\frac{\mathrm{NA}}{(\mathrm{NA}+H)}$
2) $-\mathrm{LN}(\mathrm{RIA})=K_{\text {loss }} t$
3) $K_{d}=K_{\text {loss }}-K_{\text {dilution }}$ 


\section{Results}

\section{Measurement of $\mathbf{K}_{\mathbf{d}}$}

In order to quantify protein turnover rates in enriched mitochondrial samples, organellar proteins were collected at four time points $(1,4,5$, and 7 days) following the passage of the cell culture into media containing ${ }^{15} \mathrm{~N}$-labeled salts in place of ${ }^{14} \mathrm{~N}$-labeled salts. Protein was separated using SDS-PAGE, and gel lanes excised into eight fractions that contained equal amounts of Coomassie blue staining. Gel slices were digested with trypsin and then analyzed by LC-MS/MS, with these data then searched using the Mascot algorithm 24. These results were then analyzed using the Transproteomic pipeline (TPP) in order to determine high quality peptide identifications. For proteins identified by two peptides or more, we were able to identify and measure $\mathrm{K}_{\mathrm{d}}$ for 315 proteins presented in Supplementary Table S1 and the identified peptides are provided in Supplementary Table S2. In addition, there were 8 proteins characterized by only one peptide and these proteins are listed in Supplementary Table S3. The associated peptides, which were manually inspected, given in Supplementary Table S4 and the MS/MS spectra provided in Supplementary Figure 1.

Provided in Figure 1, as an example of the workflow, is analysis of data for the IEAAFVLGQLESK peptide unique to the At3g62530 locus, which is annotated as an ARM repeat superfamily protein and is one of the more rapidly turning over proteins in our dataset. First, an extracted ion chromatogram (EIC) was generated for the monoisotopic peak and the chromatographic peak determined (Figure 1A). Then MS scans from the top of the chromatographic peak were combined to generate an average spectrum, which was then used 
to assign natural abundance (NA) and heavy $(\mathrm{H})$ peptide populations using the program Isodist ${ }^{23}$ for the different time points. Even at 1 day, the $\mathrm{H}$ population is clearly separated from NA peptides, making for facile quantitation (Figure 1B). Upon inspection of the spectra and the Isodist fits, two trends were apparent. First, the H peptides were heavier (shifted to the right in the spectrum) through time, due to an increasing proportion of ${ }^{15} \mathrm{~N}$ in the $\mathrm{H}$ peptides. Second, the relative abundance of NA peptides decreased as time progressed until they were only a few percent of the total population at 7 days. Using these data, the natural $\log$ of relative isotope abundance (RIA) was plotted against time (Figure 1C). The slope from the linear regression from this plot represents $\mathrm{K}_{\mathrm{loss}}$, the rate at which the NA population was disappearing. Besides protein degradation, dilution due to growth also contributes to a decrease in the relative proportion of the NA population. The cell culture increase in protein abundance was $0.90,2.16,2.10$, and 3.41 after $1,4,5$, and 7 day culture in ${ }^{15} \mathrm{~N}$ media. So in order to calculate protein degradation rate $\left(\mathrm{K}_{\mathrm{d}}\right)$, a dilution effect $\left(\mathrm{K}_{\text {dilution }}\right)$ of $0.168 \mathrm{~d}^{-1}$ was empirically calculated from these growth data, as indicated in the methods, and was subtracted from $\mathrm{K}_{\text {loss }}$.

\section{Turnover rates for mitochondrial proteins}

Subcellular localizations for the 323 proteins that we measured $K_{d}$ for were determined based on consensus reporting of the subcellular location database, SUBA ${ }^{25}$. From the quantified proteins, 224 were classified as localized or co-localized to the mitochondrion, 37 plastidic, 41 peroxisomal, and 21 proteins did not have an experimentally verified localization. Given the small number of polypeptides from other compartments, these proteins are viewed as contaminants, not readily allowing comparison, and are not discussed further. A histogram of $\mathrm{K}_{\mathrm{d}}$ values for the mitochondrial proteins is provided in Figure 2 and the median $\mathrm{K}_{\mathrm{d}}$ value for mitochondrial proteins was $0.079 \mathrm{~d}^{-1}$. To provide a 
perspective of the range of observed $K_{d}$ values, the ten fastest and slowest proteins are shown in Table 1. The fastest had $K_{d}$ values of $0.53-0.23$, or half-lives of 31 to 72 hours. Of the rapidly turning over proteins, the fastest protein was a heat shock chaperone type protein, grpE (At5g55200). This list also included a mitochondrial AAA-type protease and chaperone FTSH3 (At2g29080) ${ }^{26}$ and another chaperone, a mitochondrial $70 \mathrm{kDa}$ heat shock protein (HSP) (At4g37910). Also turning over rapidly was a protein involved in DNA/RNA metabolism, the glycine-rich RNA binding proteins 2 (GR-RBP2) (At4g13850). The ten slowest turning over proteins all exhibited ${ }^{15} \mathrm{~N}$ incorporation ratios similar to that which was expected by the growth rate alone $\left(\mathrm{K}_{\text {loss }}-\mathrm{K}_{\text {dilution }} \sim 0\right)$. These data indicate that the ${ }^{14} \mathrm{~N}$ proteins present at the beginning of the experiment did not significantly turnover during the 7 days of the measurements. These proteins served a variety of functions in mitochondrial metabolism and biogenesis.

\section{Links between functional category and turnover rate}

To determine if function might play a role in polypeptide stability, mitochondrial proteins were sorted into functional categories. Shown in Figure 3A is a box and whisker plot of turnover rate across these functional categories. Most of the groups had median $\mathrm{K}_{\mathrm{d}}$ values that were fairly similar, but within a group there were often outliers that varied significantly from the median values, marked in Figure $3 \mathrm{~A}$ as dots. Some functional categories exhibited somewhat quicker turnover rates, as shown by higher median $\mathrm{K}_{\mathrm{d}}$ values in Figure $3 \mathrm{~A}$. For instance, HSPs and proteins involved in DNA and RNA processes had relatively high median $\mathrm{K}_{\mathrm{d}}$ values. Additionally, one of the fastest turning over proteins was an HSP, while the list of rapidly turning over proteins included a protease and a DNA/RNA processing enzyme (Table 1). These results are consistent with our prior study where polypeptides involved in RNA and DNA metabolism were the most unstable in the whole-cell proteome from Arabidopsis cell 
culture ${ }^{14}$. In contrast, glycolytic enzymes had the slowest rate (Figure 3A). While glycolytic enzymes are not located within organelles, they have been shown to be localized to the outer surface of the outer mitochondrial membrane in a supercomplex ${ }^{27}$. Membrane carriers and transporters on the inner and outer mitochondrial membranes were consistently and slowly turning over, while many matrix located proteins in carbon and amino acid metabolism and electron transport were more variable and more rapidly turning over (Figure 3A).

In Figure $3 \mathrm{~B}, \mathrm{~K}_{\mathrm{d}}$ values are presented as a box and whisker plot for protein subunits of the mitochondrial ETC and ATP synthase complexes. From the data, CII, and CV had the tightest distribution in turnover rates, while CI, CIII and CIV had wider distributions, suggesting variation between subunits of the same protein complexes. There is considerable biological interest into how the abundance of the alternative substrate dehydrogenases (ALT), which deliver electrons to ubiquinone independently of CI and CII, are regulated ${ }^{28-30}$. Our data show that these proteins degrade at slower rates than most of the classical pathway subunits $\left(\mathrm{K}_{\mathrm{d}}\right.$ values ranging from $\left.0.00-0.08 \mathrm{~d}^{-1}\right)$. These results suggest that faster rates of synthesis are probably what underpins the accumulation of these alternative substrate dehydrogenases under environmental challenge.

\section{Variation of turnover rate amongst constituents of mitochondrial protein complexes}

Next we focused in on the spatial arrangement of 56 protein subunits of the large, multi-enzyme complexes I to $\mathrm{V}$. These data are overlaid onto a diagram of each protein complex (Figure 4). This image was supplemented with additional protein complexes also localized in the mitochondrial membranes when their location was known. Upon inspection, it was evident that the subunits localized in the soluble matrix arm of CI exhibited faster turnover rates $\left(0.12-0.18 \mathrm{~d}^{-1}\right)$ compared to integral membrane subunits $\left(0.06-0.11 \mathrm{~d}^{-1}\right)$. 
However, three subunits, a $\gamma$-carbonic anhydrase (CA) and two CA-like protein exhibited slow rates compared to other matrix located subunits $\left(0.06-0.10 \mathrm{~d}^{-1}\right)$. One subunit of CII (SDH5) had a significantly more rapid turnover rate than the rest of this complex, as did subunits QCR9 and UCRY of complex III, and COX VIa of complex IV. Complex V is composed of the matrix soluble $F_{1}$ and the integral $F_{O}$ complexes, and all of the observed subunits were from $\mathrm{F}_{1}$ and existed in a narrow range of $0.07-0.1 \mathrm{~d}^{-1}$. For comparison, prohibitin subunits that make up the $>1 \mathrm{M}$ Da prohibitin complex were turning over fairly slowly with $\mathrm{K}_{\mathrm{d}}$ values averaging $0.05 \mathrm{~d}^{-1}$ and various alternative substrate dehydrogenases which are known to be located on both sides of the inner membrane were also slow $\left(\mathrm{K}_{\mathrm{d}} 0.00\right.$ $0.08 \mathrm{~d}^{-1}$ ). The protease FtsH3 in the inner membrane turned over much more rapidly with a $\mathrm{K}_{\mathrm{d}}$ of $0.38 \mathrm{~d}^{-1}$.

\section{Turnover of Arabidopsis proteins in comparison with mouse}

To determine if degradation rate is a conserved characteristic of specific proteins in mitochondria, a comparison was made between the $\mathrm{K}_{\mathrm{d}}$ values of Arabidopsis mitochondrial proteins we have measured and those reported for mitochondrial proteins from heart and liver tissues of mouse ${ }^{15}$. We have plotted out all groups of mitochondrial proteins in a histogram (Figure 5A). Comparing between the two groups of mouse proteins, the liver mitochondrial proteins turned over more rapidly than heart mitochondrial proteins, with median $\mathrm{K}_{\mathrm{d}}$ values of $0.16 \mathrm{~d}^{-1}$ and $0.04 \mathrm{~d}^{-1}$ respectively. Our plant mitochondrial proteins fell between the two groups but the median value was closest to the heart population. Given the similarity in turnover of the three datasets, we felt this corroborated the quality of our preparations and measurements of $\mathrm{K}_{\mathrm{d}}$. To investigate whether a protein's turnover rate is conserved across biological taxa, we used the BLAST algorithm ${ }^{31}$ to align the mitochondrial protein sequences quantified from a mouse mitochondrial proteome dataset to the closest Arabidopsis homolog. 
Considering mouse proteins that matched to our dataset with an E-value less than $10^{-20}, 49$ pairs were identified from the heart and 55 from the liver (Supplementary Table 2) and the matches are plotted in Figure 5B. A Spearman rank correlation between the mouse heart mitochondrial proteins and Arabidopsis mitochondrial proteins yielded a correlation of only 0.18 and was insignificant $(\mathrm{P}=0.21)$. In comparison, the mouse liver and Arabidopsis matches produced a correlation of 0.46 that was significant $(\mathrm{P}=0.0004)$ but neither correlation was particularly strong. Notably, the correlation between the same mitochondrial proteins in the liver and heart tissues was only $0.50\left(p=2.2 \times 10^{-16}\right)^{4}$. When considering the subset of proteins that were present in heart and liver datasets and that matched to our mitochondrial dataset, there were 44 proteins and the Spearman rank correlation was 0.71 and was significant $\left(\mathrm{P}=7.3 \times 10^{-8}\right) \quad$ Given that tissue to tissue variation can be significant within the same organism as well as the phylogenetic separation of plants and animals, the low correlations suggest that degradation rates of specific proteins may be highly dependent on local factors such as the state of the tissue and the network of active proteases, and less so about the accessibility or physical structure of the protein itself. The single high turnover value protein shared by both mouse tissues and Arabidopsis mitochondria was the heat shock chaperone type protein, grpE (Figure 5B).

\section{Discussion}

Protein turnover is known to play an integral role in several aspects of plant physiology. For example, the rapid replacement of damaged photosynthetic proteins is crucial for maintaining carbon fixation and under environmental stress inadequate protein turnover can limit primary production ${ }^{32}$. Additionally, the role of protein degradation is known to play an important role in several aspects of hormone signaling in plants $1,33,34$ while also participating in the day to day operations of the cell through regulation of circadian oscillations ${ }^{35}$. Given that high-volume measurement of $K_{s}$ and $K_{d}$ is still a 
relatively new area in proteomic research, application of these approaches to a variety of biological contexts will facilitate the generation of new hypotheses for future experiments. Most protein turnover studies to date have focused on analysis of whole-protein extracts and have produced large datasets that yielded novel biological insight ${ }^{5,8,17}$. However, despite the dramatic improvement in proteomic instrumentation over the last decade, these technologies still have a restricted dynamic range, which will limit the depth of turnover studies of crude lysates. Alternatively, by focusing our analysis on an enriched organellar fraction we believe we can gain greater insight into specific biological processes, which are often compartmentalized within relatively low abundance organelles.

\section{DNA/RNA metabolism and stress responsive proteins rapidly turn over in Arabidopsis organelles}

Typically, proteins with fast turnover rates are believed to represent potential points of control and regulation. Several enzymes involved in DNA/RNA processes inside organelles turned over rapidly, which is consistent with our earlier observations of nuclear components involved in DNA/RNA processes in whole extracts of Arabidopsis cell culture ${ }^{14}$. GR-RBPs play complex roles as RNA splicing enzymes or RNA chaperones and stability factors ${ }^{36}$. It is not clear why, inherently, these proteins should be rapidly turning over as they have a continuing maintenance function in mitochondria in managing the transcript pool from transcription of the mitochondrial genome. However, given that they are stress inducible genes in plants ${ }^{36}$, tight transcriptional control of their abundance may be important.

Other proteins exhibiting rapid degradation included specific proteases, heat shock chaperones or proteins which were associated with oxidative stress. All of these are proteins involved in stress response or response to environmental damage. Rapid turnover of these proteins, relative to the rest of the organelle proteome, will better enable transcriptional 
processes to regulate their presence and thus their function. Comparisons to lists of protein turnover rates in mitochondria of mouse also suggest these categories have higher than average turnover rates ${ }^{15}$.

\section{Glycolytic enzymes protected by mitochondrial attachment}

At the other end of the spectrum, the slowest turnover functional category was the glycolytic machinery found in the organelle pellets. While glycolysis is a series of cytosolic reactions, a portion of the glycolytic enzymes form a supercomplex that is physically tethered to the outer mitochondrial membrane in plants, so that a mitochondrial-enriched sample would contain only a subpopulation of the glycolytic machinery of the cell as a whole ${ }^{27}$. The turnover rates for the four observed glycolytic enzymes were very slow, with a median $\mathrm{K}_{\mathrm{d}}$ of $0.03 \mathrm{~d}^{-1}$ and a range of $0.02-0.08 \mathrm{~d}^{-1}$. As a comparison, in prior work from Arabidopsis cell culture, cytosolic glycolytic enzymes had a median value $0.2 \mathrm{~d}^{-1}$, with a range of $0.13-0.30 \mathrm{~d}^{-1}$ ${ }^{14}$, which would represent an average of all subcellular pools. To assess whether this discrepancy in $\mathrm{K}_{\mathrm{d}}$ values was pervasive across all proteins identified in both studies, we compared $\mathrm{K}_{\mathrm{d}}$ values for a set of 12 mitochondrial matrix enzymes that were detected in both this study and the prior work ${ }^{14}$. This analysis showed that the two studies report highly similar $\mathrm{K}_{\mathrm{d}}$ values for this set of matrix proteins, with the previous study reporting a median $\mathrm{K}_{\mathrm{d}}$ of $0.09 \mathrm{~d}^{-1}$ (range: $0.04-0.27 \mathrm{~d}^{-1}$ ), which closely corresponds with the median $\mathrm{K}_{\mathrm{d}} 0.08 \mathrm{~d}^{-1}$ (range 0.06-0.27 $\mathrm{d}^{-1}$ ) in the work presented here. As specific examples, consider succinylCoA ligase ( $0.06 \mathrm{~d}^{-1}$ in the prior study and $0.07 \mathrm{~d}^{-1}$ in this study), and malate dehydrogenase 2 $\left(0.06 \mathrm{~d}^{-1}\right.$ in the prior study and $0.08 \mathrm{~d}^{-1}$ in this study). These similar $\mathrm{K}_{\mathrm{d}}$ values demonstrate the consistency between both studies for established mitochondrial matrix proteins. In combination, these data would suggest that the OMM-localized glycolytic supercomplexes in organelle preparations are protected from degradation and are much more stable in 
comparison to the wider cellular population of glycolytic enzymes. This stabilizing influence of attachment to mitochondria provides new information regarding the consequences of this attachment, which previously has only been considered in the context of providing substrate channeling from glycolysis to the TCA cycle ${ }^{27}$.

\section{Variation in the turnover of protein complexes}

Another area of interest with regards to protein turnover is how protein complexes and their respective subunits are recycled, be it piecemeal or as entire complexes or subcomplexes. Differential turnover rates between subunits of a complex may indicate if specific components are most liable to damage during their functioning, and are turned over independently of the complex as a whole. In addition, analysis of the subunits of complexes may provide insight not only into complex recycling but also provide information about complex assembly. In a range of published datasets, subunits of protein complexes have been shown to typically turnover at the same rate $5,8,14,16$. However, closer examinations of the mitochondrial $\mathrm{CI}$ and $\mathrm{CV}$ of plants has provided insight into complex assembly as well as components of the complexes that appear to be turned over more quickly, likely as a result of being intermediates in synthesis of the larger complexes ${ }^{18,19}$. In both of these earlier studies, the analysis was of BN-PAGE, separated proteins and $\mathrm{K}_{\mathrm{d}}$ values presented were for holocomplexes and subcomplexes. In comparison, our data represent an average of the holocomplexes, subcomplexes, and uncomplexed proteins. However, similarities between this and the other datasets were apparent. Collectively, the subunits of the matrix-facing soluble arm of CI turned over at a faster rate compared to the rest of the complex, presumably as a result of damage and recycling, whereas the membranous components were slower. Additionally, the ancestral CI component of CA and CA-like proteins had slower turnover values than the rest of the membrane aim, similar to our prior study where gel bands were 
studied individually ${ }^{19}$. For CV, all the observed subunits identified here exhibited similar turnover rates, suggesting that the complex effectively turns over as a unit, even though smaller populations of differentially turning over $F_{1}$ subcomplexes can be separated on native gels ${ }^{18}$.

There are no prior observations regarding protein turnover in CII, CIII, and CIV of the mitochondrial ETC in plants. For CII, the canonical SDH subunits as well as two plant specific SDH subunits all had similar $\mathrm{K}_{\mathrm{d}}$ values. However, the plant specific subunit SDH5 displayed a turnover rate that was three times faster than the rest of the complex. Little to nothing is known regarding the function of these subunits, although it is speculated that they are regulatory in nature rather than catalytic ${ }^{37}$. Therefore, the turnover data presented here could suggest that the rapid proteolytic degradation rate of SDH5 needs to be considered alongside study of its potential role in regulation of the complex. Most of the CIII subunits had a slow turnover, consistent with being subunits of the same complex, with the exception of subunits 10 and 11 (QCR9 and UCRY), which were degraded at a significantly faster rate. These subunits are both small $(<10 \mathrm{kDa})$ and are known to be physically located next to each other in the complex. It is conceivable this portion of the complex is prone to chemical damage or dissociation. For complex IV, most of the subunits possessed similar $K_{d}$ values with the exception of COX VIa, which was approximately three times faster than the rest of the complex. In both mammals and yeast, this protein has been suggested to play a regulatory rather than a catalytic role in COX function ${ }^{38,39}$. In mammals, tissue specific isoforms of COXVIa are found and have been linked to differential regulation of COX function by changing the circumstances under which COX becomes ATP-inhibited. ATP-inhibition leading to a slip in proton pumping, is found permanently when the liver-type COXVIa is present (subunit VIaL) but is only observed at high intramitochondrial ATP/ADP ratios when 
the heart-type isozyme (subunit VIaH) is present ${ }^{38}$. It is conceivable in plants that COX VIa would also play a regulatory role. There is only one isoform of COX VIa in Arabidopsis, which should simplify genetic analysis of the role of COX VIa in CIV function.

\section{The role of internal proteolysis vs autophagy in organelle turnover}

The degree to which various proteolytic pathways contribute to organelle protein turnover and organellar homeostasis in plants remains unclear. There are many compartment specific proteases present in different organelle types ${ }^{26,40,41}$ and the plastid is also known to recycle proteins from the outer- membrane via the ubiquitin/proteasomal pathway ${ }^{42}$. Additionally, mitochondria regularly engage in fusion and fission in plants and animals, and it is hypothesized in animals that this allows damaged contents such as proteins to be sorted and targeted to the lysosome for degradation ${ }^{43}$. The Parkin and PINK proteins are components of this machinery, and it is believed that human pathologies such as Parkinson's disease may be caused by mitochondrial dysfunction when these repair mechanisms fail. Therefore, this process is of much interest in biomedical research ${ }^{44}$. In contrast, very little is known regarding the mitophagy or autophagy of organelles in plant systems. Recent studies have demonstrated the importance of autophagy in plant survival under environmental stress ${ }^{45}$, the importance of autophagy in the physiology of seed filling ${ }^{46}$ and a role for autophagy in plastid degradation in darkened leaves ${ }^{47}$. However, the relative importance of this process to the total protein turnover rate in plants is not clear. In a large scale analysis of protein turnover in multiple tissues of mouse, mitochondrial proteins had $\mathrm{K}_{\mathrm{d}}$ values that were slow and only extended over a narrow range, leading the authors to suggest that autophagy may be a primary determinant in mitochondrial protein turnover in this tissue ${ }^{5}$. In contrast, a more detailed study that focused on turnover of mitochondrial proteins in mice reported $\mathrm{K}_{\mathrm{d}}$ values which varied by more than two orders of magnitude, leading these authors to conclude that 
mitophagy did not play a clear and overwhelming role in mitochondrial protein turnover ${ }^{15}$. In our previous study of whole cell lysates of plants, relatively few mitochondrial proteins were quantified and the proteins that were quantified were from abundant protein such as those from the TCA cycle and ETC components and most were of a similar magnitude ${ }^{14}$. When considering our new dataset, the $\mathrm{K}_{\mathrm{d}}$ values of the organelle proteins spanned more than a 50fold range. Given this broad range of turnover rates, it is difficult to conclude that most mitochondrial proteins are being turned over en masse by simple mitophagy-like processes in plants. However, we cannot rule out the possibility that sorting of damaged proteins in combination with mitophagy plays a significant role for the major machinery that has a similar slow rate of turnover. One possible mechanism is that the occurrence of mitochondrial fusion and fission events provides an opportunity to sort damaged mitochondrial proteins into vesicles that are then trafficked to the vacuole for degradation.

\section{Conclusion}

Overall, these results point out the value of more detailed protein turnover studies conducted at the subcellular/organellar level and even at the complex and subcomplex level to undercover the degree of variation in protein turnover characteristics. We have highlighted a range of proteins in complexes which for the first time can be singled out as having unusual turnover characteristics. Future studies will need to attempt to alter turnover rates by developmental and environmental cues to explore if there is dynamics in this process for defining the proteomes of plant mitochondria. 


\section{Acknowledgements}

This work was supported by the Australian Research Council (ARC) ARC Centre of Excellence for Plant Energy Biology (CE0561495), an ARC Linkage Grant (LP120200102), and AHM is funded as an ARC Future Fellow (FT110100242).

\section{References}

(1) Bensimon, A.; Heck, A. J.; Aebersold, R. Mass spectrometry-based proteomics and network biology. Annu Rev Biochem 2012, 81, 379-405.

(2) Claydon, A. J.; Beynon, R. Proteome dynamics: revisiting turnover with a global perspective. Mol Cell Proteomics 2012, 11, 1551-65.

(3) Hinkson, I. V.; Elias, J. E. The dynamic state of protein turnover: It's about time. Trends Cell Biol 2011, 21, 293-303.

(4) Pratt, J. M.; Petty, J.; Riba-Garcia, I.; Robertson, D. H.; Gaskell, S. J.; Oliver, S. G.; Beynon, R. J. Dynamics of protein turnover, a missing dimension in proteomics. Mol Cell Proteomics 2002, 1, 579-91.

(5) Price, J. C.; Guan, S.; Burlingame, A.; Prusiner, S. B.; Ghaemmaghami, S. Analysis of proteome dynamics in the mouse brain. Proc Natl Acad Sci U S A 2010, 107, 14508-13.

(6) Doherty, M. K.; McClean, L.; Edwards, I.; McCormack, H.; McTeir, L.; Whitehead, C.; Gaskell, S. J.; Beynon, R. J. Protein turnover in chicken skeletal muscle: understanding protein dynamics on a proteome-wide scale. Br Poult Sci 2004, 45 Suppl 1, S27-8.

(7) Zhang, Y.; Reckow, S.; Webhofer, C.; Boehme, M.; Gormanns, P.; Egge-Jacobsen, W. M.; Turck, C. W. Proteome scale turnover analysis in live animals using stable isotope metabolic labeling. Anal Chem 2011, 83, 1665-72. 
(8) Trotschel, C.; Albaum, S. P.; Wolff, D.; Schroder, S.; Goesmann, A.; Nattkemper, T. W.; Poetsch, A. Protein turnover quantification in a multilabeling approach: from data calculation to evaluation. Mol Cell Proteomics 2012, 11, 512-26.

(9) Martin, S. F.; Munagapati, V. S.; Salvo-Chirnside, E.; Kerr, L. E.; Le Bihan, T. Proteome turnover in the green alga Ostreococcus tauri by time course ${ }^{15} \mathrm{~N}$ metabolic labeling mass spectrometry. J Proteome Res 2012, 11, 476-86.

(10) Yang, X. Y.; Chen, W. P.; Rendahl, A. K.; Hegeman, A. D.; Gray, W. M.; Cohen, J. D. Measuring the turnover rates of Arabidopsis proteins using deuterium oxide: an auxin signaling case study. Plant $J$ 2010, 63, 680-95.

(11) Kushner, D. J.; Baker, A.; Dunstall, T. G. Pharmacological uses and perspectives of heavy water and deuterated compounds. Can J Physiol Pharmacol 1999, 77, 79-88.

(12) Lecchi, S.; Nelson, C. J.; Allen, K. E.; Swaney, D. L.; Thompson, K. L.; Coon, J. J.; Sussman, M. R.; Slayman, C. W. Tandem phosphorylation of Ser-911 and Thr-912 at the C terminus of yeast plasma membrane $\mathrm{H}+$-ATPase leads to glucose-dependent activation. $J$ Biol Chem 2007, 282, 35471-81.

(13) Skirycz, A.; Memmi, S.; De Bodt, S.; Maleux, K.; Obata, T.; Fernie, A. R.; Devreese, B.; Inze, D. A reciprocal ${ }^{15} \mathrm{~N}$-labeling proteomic analysis of expanding Arabidopsis leaves subjected to osmotic stress indicates importance of mitochondria in preserving plastid functions. J Proteome Res 2011, 10, 1018-29.

(14) Li, L.; Nelson, C. J.; Solheim, C.; Whelan, J.; Millar, A. H. Determining degradation and synthesis rates of arabidopsis proteins using the kinetics of progressive ${ }^{15} \mathrm{~N}$ labeling of two-dimensional gel-separated protein spots. Mol Cell Proteomics 2012, 11, M111 010025.

(15) Kim, T. Y.; Wang, D.; Kim, A. K.; Lau, E.; Lin, A. J.; Liem, D. A.; Zhang, J.; Zong, N. C.; Lam, M. P.; Ping, P. Metabolic labeling reveals proteome dynamics of mouse mitochondria. Mol Cell Proteomics 2012, 11, 1586-94. 
(16) Boisvert, F. M.; Ahmad, Y.; Gierlinski, M.; Charriere, F.; Lamont, D.; Scott, M.; Barton, G.; Lamond, A. I. A quantitative spatial proteomics analysis of proteome turnover in human cells. Mol Cell Proteomics 2012, 11, M111 011429.

(17) Cambridge, S. B.; Gnad, F.; Nguyen, C.; Bermejo, J. L.; Kruger, M.; Mann, M. Systems-wide proteomic analysis in mammalian cells reveals conserved, functional protein turnover. J Proteome Res 2011, 10, 5275-84.

(18) Li, L.; Carrie, C.; Nelson, C.; Whelan, J.; Millar, A. H. Accumulation of newly synthesized F1 in vivo in arabidopsis mitochondria provides evidence for modular assembly of the plant F1Fo ATP synthase. J Biol Chem 2012, 287, 25749-57.

(19) Li, L.; Nelson, C. J.; Carrie, C.; Gawryluk, R. M.; Solheim, C.; Gray, M. W.; Whelan, J.; Millar, A. H. Subcomplexes of ancestral respiratory complex I subunits rapidly turn over in vivo as productive assembly intermediates in Arabidopsis. J Biol Chem 2013, 288, 5707 17.

(20) Baerenfaller, K.; Grossmann, J.; Grobei, M. A.; Hull, R.; Hirsch-Hoffmann, M.; Yalovsky, S.; Zimmermann, P.; Grossniklaus, U.; Gruissem, W.; Baginsky, S. Genome-scale proteomics reveals Arabidopsis thaliana gene models and proteome dynamics. Science 2008, $320,938-41$.

(21) Schweikl, H.; Klein, U.; Schindlbeck, M.; Wieczorek, H. A vacuolar-type ATPase, partially purified from potassium transporting plasma membranes of tobacco hornworm midgut. J Biol Chem 1989, 264, 11136-42.

(22) Huttlin, E. L.; Hegeman, A. D.; Harms, A. C.; Sussman, M. R. Comparison of full versus partial metabolic labeling for quantitative proteomics analysis in Arabidopsis thaliana. Mol Cell Proteomics 2007, 6, 860-81. 
(23) Sperling, E.; Bunner, A. E.; Sykes, M. T.; Williamson, J. R. Quantitative analysis of isotope distributions in proteomic mass spectrometry using least-squares Fourier transform convolution. Anal Chem 2008, 80, 4906-17.

(24) Perkins, D. N.; Pappin, D. J.; Creasy, D. M.; Cottrell, J. S. Probability-based protein identification by searching sequence databases using mass spectrometry data. Electrophoresis 1999, 20, 3551-67.

(25) Heazlewood, J. L.; Tonti-Filippini, J.; Verboom, R. E.; Millar, A. H. Combining experimental and predicted datasets for determination of the subcellular location of proteins in Arabidopsis. Plant Physiol 2005, 139, 598-609.

(26) Janska, H.; Kwasniak, M.; Szczepanowska, J. Protein quality control in organelles AAA/FtsH story. Biochim Biophys Acta 2013, 1833, 381-7.

(27) Giege, P.; Heazlewood, J. L.; Roessner-Tunali, U.; Millar, A. H.; Fernie, A. R.; Leaver, C. J.; Sweetlove, L. J. Enzymes of glycolysis are functionally associated with the mitochondrion in Arabidopsis cells. Plant Cell 2003, 15, 2140-51.

(28) Ishizaki, K.; Schauer, N.; Larson, T. R.; Graham, I. A.; Fernie, A. R.; Leaver, C. J. The mitochondrial electron transfer flavoprotein complex is essential for survival of Arabidopsis in extended darkness. Plant J 2006, 47, 751-60.

(29) Rasmusson, A. G.; Geisler, D. A.; Møller, I. M. The multiplicity of dehydrogenases in the electron transport chain of plant mitochondria. . Mitochondrion 2008, 8, 47-60.

(30) Rasmusson, A. G.; Soole, K. L.; Elthon, T. E. Alternative NAD(P)H dehydrogenases of plant mitochondria. Annu Rev Plant Biol 2004, 55, 23-39.

(31) Altschul, S. F.; Gish, W.; Miller, W.; Myers, E. W.; Lipman, D. J. Basic local alignment search tool. J Mol Biol 1990, 215, 403-10.

(32) Murata, N.; Takahashi, S.; Nishiyama, Y.; Allakhverdiev, S. I. Photoinhibition of photosystem II under environmental stress. Biochim Biophys Acta 2007, 1767, 414-21. 
(33) Kepinski, S.; Leyser, O. The Arabidopsis F-box protein TIR1 is an auxin receptor. Nature 2005, 435, 446-51.

(34) Liu, H.; Stone, S. L. Abscisic acid increases Arabidopsis ABI5 transcription factor levels by promoting KEG E3 ligase self-ubiquitination and proteasomal degradation. Plant Cell 2010, 22, 2630-41.

(35) Kim, W. Y.; Fujiwara, S.; Suh, S. S.; Kim, J.; Kim, Y.; Han, L.; David, K.; Putterill, J.; Nam, H. G.; Somers, D. E. ZEITLUPE is a circadian photoreceptor stabilized by GIGANTEA in blue light. Nature 2007, 449, 356-60.

(36) Fusaro, A. F.; Bocca, S. N.; Ramos, R. L.; Barroco, R. M.; Magioli, C.; Jorge, V. C.; Coutinho, T. C.; Rangel-Lima, C. M.; De Rycke, R.; Inze, D.; Engler, G.; Sachetto-Martins, G. AtGRP2, a cold-induced nucleo-cytoplasmic RNA-binding protein, has a role in flower and seed development. Planta 2007, 225, 1339-51.

(37) Huang, S.; Taylor, N. L.; Narsai, R.; Eubel, H.; Whelan, J.; Millar, A. H. Functional and composition differences between mitochondrial complex II in Arabidopsis and rice are correlated with the complex genetic history of the enzyme. Plant Mol Biol 2010, 72, 331-42.

(38) Kadenbach, B.; Huttemann, M.; Arnold, S.; Lee, I.; Bender, E. Mitochondrial energy metabolism is regulated via nuclear-coded subunits of cytochrome c oxidase. Free Radic Biol Med 2000, 29, 211-21.

(39) Taanman, J. W.; Capaldi, R. A. Subunit VIa of yeast cytochrome c oxidase is not necessary for assembly of the enzyme complex but modulates the enzyme activity. Isolation and characterization of the nuclear-coded gene. J Biol Chem 1993, 268, 18754-61.

(40) Schuhmann, H.; Adamska, I. Deg proteases and their role in protein quality control and processing in different subcellular compartments of the plant cell. Physiol Plant 2012, $145,224-34$. 
(41) Clarke, A. K. The chloroplast ATP-dependent Clp protease in vascular plants - new dimensions and future challenges. Physiol Plant 2012, 145, 235-44.

(42) Ling, Q.; Huang, W.; Baldwin, A.; Jarvis, P. Chloroplast biogenesis is regulated by direct action of the ubiquitin-proteasome system. Science 2012, 338, 655-9.

(43) Fischer, F.; Hamann, A.; Osiewacz, H. D. Mitochondrial quality control: an integrated network of pathways. Trends Biochem Sci 2012, 37, 284-92.

(44) Xilouri, M.; Stefanis, L. Autophagic pathways in Parkinson disease and related disorders. Expert Rev Mol Med 2011, 13, e8.

(45) Araujo, W. L.; Tohge, T.; Ishizaki, K.; Leaver, C. J.; Fernie, A. R. Protein degradation - an alternative respiratory substrate for stressed plants. Trends Plant Sci 2011, $16,489-98$.

(46) Guiboileau, A.; Yoshimoto, K.; Soulay, F.; Bataille, M. P.; Avice, J. C.; MasclauxDaubresse, C. Autophagy machinery controls nitrogen remobilization at the whole-plant level under both limiting and ample nitrate conditions in Arabidopsis. New Phytol 2012, 194, 73240.

(47) Wada, S.; Ishida, H.; Izumi, M.; Yoshimoto, K.; Ohsumi, Y.; Mae, T.; Makino, A. Autophagy plays a role in chloroplast degradation during senescence in individually darkened leaves. Plant Physiol 2009, 149, 885-93.

(48) Klodmann, J.; Senkler, M.; Rode, C.; Braun, H. P. Defining the protein complex proteome of plant mitochondria. Plant Physiol 2011, 157, 587-98.

(49) Meyer, E. H. Proteomic investigations of complex I composition: how to define a subunit? Front Plant Sci 2012, 3, 106.

(50) Huang, S.; Millar, A. H. Succinate dehydrogenase: the complex roles of a simple enzyme. Curr Opin Plant Biol 2013. 
(51) Fellman, V. Mitochondrial complex III deficiencies in the newborn infant. Drug Discovery Today: Disease Mechanisms 2006, 3, 421-427.

(52) Tsukihara, T.; Aoyama, H.; Yamashita, E.; Tomizaki, T.; Yamaguchi, H.; ShinzawaItoh, K.; Nakashima, R.; Yaono, R.; Yoshikawa, S. The whole structure of the 13-subunit oxidized cytochrome c oxidase at 2.8 A. Science 1996, 272, 1136-44.

(53) Buckel, W.; Thauer, R. K. Energy conservation via electron bifurcating ferredoxin reduction and proton/ $\mathrm{Na}(+)$ translocating ferredoxin oxidation. Biochim Biophys Acta 2013, 1827, 94-113.

(54) Leys, D.; Basran, J.; Talfournier, F.; Sutcliffe, M. J.; Scrutton, N. S. Extensive conformational sampling in a ternary electron transfer complex. Nat Struct Biol 2003, 10, 219-25.

(55) Iwata, M.; Lee, Y.; Yamashita, T.; Yagi, T.; Iwata, S.; Cameron, A. D.; Maher, M. J. The structure of the yeast NADH dehydrogenase (Ndi1) reveals overlapping binding sites for water- and lipid-soluble substrates. Proc Natl Acad Sci U S A 2012, 109, 15247-52.

(56) Escobar-Henriques, M.; Langer, T. Mitochondrial shaping cuts. Biochim Biophys Acta 2006, 1763, 422-9. 
Table Legend

Table 1 The ten fastest and ten slowest turnover proteins in our Arabidopsis mitochondrial fraction. AGI column contains gene identification number assigned by the Arabidopsis genome initiative. Annotation column contains protein function assigned by TAIR10. $\mathrm{K}_{\mathrm{d}}$ column contains degradation rate measured in this study.

Fastest

\begin{tabular}{|r|r|r|}
\hline AGI & Annotation & $\left.\mathbf{K}_{\mathbf{d}} \mathbf{( d}^{\mathbf{- 1}}\right)$ \\
\hline At5g55200 & Co-chaperone grpE & 0.53 \\
\hline At2g29080 & FtsH protease 3 & 0.38 \\
\hline At3g62530 & PBS lyase HEAT-like repeat-containing & 0.33 \\
\hline At2g34630 & Geranyl diphosphate synthase (GPS1) & 0.28 \\
\hline At4g33010 & Glycine decarboxylase P-protein 1 (GLDP1) & 0.27 \\
\hline At4g13850 & Glycine-rich RNA binding protein 2 (GR- & 0.27 \\
\hline At4g37830 & Cytochrome c oxidase subunit (COX VIa) & 0.27 \\
\hline At4g37910 & Mitochondrial heat shock protein (HSP70-1) & 0.27 \\
\hline At5g10860 & CBS domain-containing protein & 0.25 \\
\hline At1g31760 & SWIB complex BAF60b domain-containing & 0.23 \\
\hline
\end{tabular}

Slowest

\begin{tabular}{|c|c|c|}
\hline AGI & Annotation & $K_{d}\left(d^{-1}\right)$ \\
\hline At4g15940 & Fumarylacetoacetate hydrolase & 0.00 \\
\hline At4g05020 & NAD(P)H dehydrogenase B2 (NDB2) & 0.00 \\
\hline At5g56090 & cytochrome c oxidase 15 (COX15) & 0.00 \\
\hline At4g00570 & Malate oxidoreductase (malic enzyme) & 0.00 \\
\hline At5g65750 & $\begin{array}{r}\text { Oxoglutarate dehydrogenase E1 subunit } \\
\text { (OGDC E1) }\end{array}$ & 0.00 \\
\hline At3g13930 & $\begin{array}{r}\text { Dihydrolipoamide S-acetyltransferase (PDC } \\
\text { E2) }\end{array}$ & 0.00 \\
\hline At2g41380 & Embryo-abundant protein & 0.00 \\
\hline At3g13490 & Lysine tRNA ligase (OVA5) & 0.00 \\
\hline At1g55160 & unknown function protein & 0.01 \\
\hline At2g42210 & Import translocase Tim17/Tim22/Tim 23 family & 0.02 \\
\hline
\end{tabular}




\section{Figure Legends}

Figure 1 Workflow used to calculate $K_{d}$ of the peptide IEAAFVLGQLESK for At3g62530, an ARM repeat superfamily protein. (A) Blue chromatogram shows an extracted ion chromatogram generated for the monoisotopic peak of interest for all timepoints, while the red chromatogram shows a Gaussian peak fitted to the raw data. The grey box shows the time window encompassing the top of the fitted peak \pm one standard deviation. MS scans that fell within this window were combined to generate an average spectrum that was used for subsequent calculation of $\mathrm{K}_{\mathrm{d}}$. (B) Representative spectra from 1, 4, and 7 days, which were then fitted by the Isodist algorithm to assign natural abundance (NA) and heavy (H) populations for each spectrum. The red spectrum above represents the observed average spectrum, while the blue spectrum below is the fitted spectrum determined using Isodist. (C) Natural logarithm of Relative Isotope Abundance (RIA) plotted against time. The slope coefficient of the linear equation fitted to this plot is used to calculate $\mathrm{K}_{\mathrm{d}}$.

Figure 2 Histogram of protein $\mathrm{K}_{\mathrm{d}}$ values plotted for mitochondrial, proteins as assigned by the SUBA (suba.plantenergy.uwa.edu.au) website. The median value is plotted as a dashed line.

Figure 3 (A) Box and whisker plots of $K_{d}$ values for mitochondrial proteins sorted by functional categorization, as assigned by the MapCave website (http://mapman.gabipd.org/web/guest/mapcave), with outliers represented by dots. Abbreviations: AA met, amino acid metabolism; ATP syn, ATP synthase DNA/RNA, DNA/RNA processes; ETC, electron transport chain; ETC ass, ETC assembly; HSP, heat 
shock proteins; IM carrier, inner membrane carrier; NA met, nucleic acid metabolism, OM carrier, outer membrane carrier; OX stress, oxidative stress; Protease rel, protease related; Prot IM tran, protein inner membrane transport; Prot syn, protein synthesis, S met, sulfur metabolism; TCA, tricarboxylic acid cycle. (B) Box and whisker plots of $\mathrm{K}_{\mathrm{d}}$ values for mitochondrial respiratory complex subunits, with outliers indicated by dots.

Figure 4 Color-coded image of $\mathrm{K}_{\mathrm{d}}$ values for proteins of the mitochondrial Electron Transport Chain (ETC), as well as three other complexes: the FTSH protease complex, the prohibitin complex, and the VDAC import complex. Abbreviations: ETF, electron transfer flavoprotein; FTSH, filamentation temperature sensitive protease; PHB, prohibitin; VDAC, voltage-dependent anion channel. Subunits locations, shapes and abbreviations are based on models published before: $\mathrm{CI}^{19,48,49}, \mathrm{CII}^{50}, \mathrm{CIII}^{51}, \mathrm{CIV}^{52}, \mathrm{CV}^{18}$, EFT complex ${ }^{53,54}, \mathrm{NDB}^{55}$, FtsH and prohibitin complex ${ }^{56}$.

Figure 5 (A) Histogram of $\mathrm{K}_{\mathrm{d}}$ values for Arabidopsis mitochondrial proteins and mitochondrial proteins derived from two different tissues of mouse, heart and liver ${ }^{15}$. Marked in blue the Arabidopsis dataset, in purple the heart dataset and in brown the liver dataset. The three colors merge where datasets overlap. (B) Left, scatter plot of $K_{d}$ values for mitochondrial proteins derived from mouse heart against $\mathrm{K}_{\mathrm{d}}$ values for Arabidopsis mitochondrial proteins. Center, scatter plot of $\mathrm{K}_{\mathrm{d}}$ values for mitochondrial proteins derived from mouse liver against $\mathrm{K}_{\mathrm{d}}$ values for Arabidopsis mitochondrial proteins. Right, scatter plot of $K_{d}$ values for mitochondrial proteins derived from mouse liver against $K_{d}$ values for mitochondrial proteins derived from mouse heart. All mitochondrial proteins detected in the dataset are represented by blue squares, while the subset of mitochondrial proteins matched to Arabidopsis homologs detected in this study are marked by purple squares. 


\section{Summary of Supplemental Data}

This material is available free of charge via the Internet at http://pubs.acs.org.

Supplementary Table S1. Protein Degradation Rates for Organelle Proteins from Arabidopsis thaliana

Supplementary Table S2: Peptides identified for each protein and indication of which peptides were used in the quantitation shown in Supplementary Table S1

Supplementary Table S3. Degradation rates of proteins derived from eight single peptides.

Supplementary Table S4. Identification of 8 proteins based on single peptides used in the quantitation shown in Supplementary Table S3 (spectra of peptides are outlined in Supplemental Figure 1).

Supplemental Figure S1. Mass spectra evidence for eight single peptide based claims of identification. 
B.
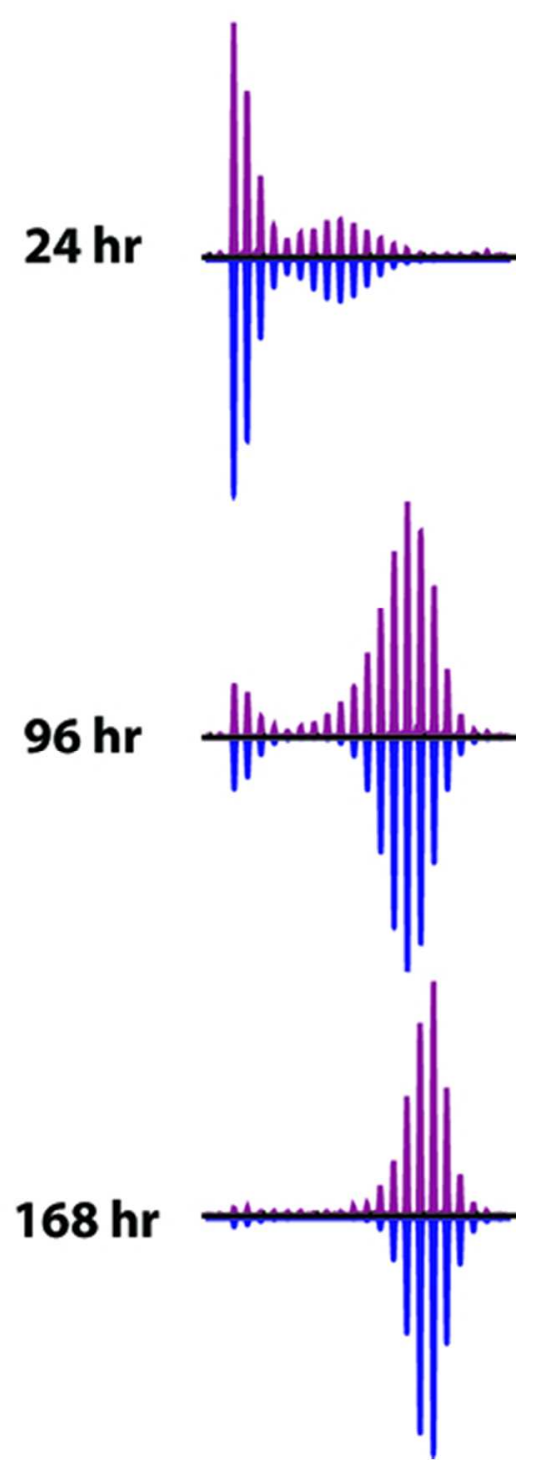

Figure 1 Workflow used to calculate Kd of the peptide IEAAFVLGQLESK for At3g62530, an ARM repeat superfamily protein. (A) Blue chromatogram shows an extracted ion chromatogram generated for the monoisotopic peak of interest for all timepoints, while the red chromatogram shows a Gaussian peak fitted to the raw data. The grey box shows the time window encompassing the top of the fitted peak \pm one standard deviation. MS scans that fell within this window were combined to generate an average spectrum that was used for subsequent calculation of $\mathrm{Kd}$. (B) Representative spectra from 1, 4, and 7 days, which were then fitted by the Isodist algorithm to assign natural abundance (NA) and heavy $(H)$ populations for each spectrum. The red spectrum above represents the observed average spectrum, while the blue spectrum below is the fitted spectrum determined using Isodist. (C) Natural logarithm of Relative Isotope Abundance (RIA) plotted against time. The slope coefficient of the linear equation fitted to this plot is used to calculate $\mathrm{Kd}$. 


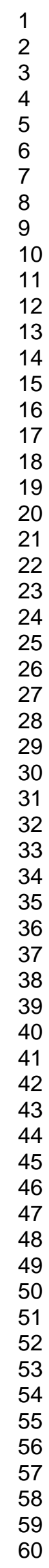


Figure 2 Histogram of protein Kd values plotted for mitochondrial, proteins as assigned by the SUBA (suba.plantenergy.uwa.edu.au) website. The median value is plotted as a dashed line. $150 \times 87 \mathrm{~mm}(300 \times 300$ DPI $)$ 
A.

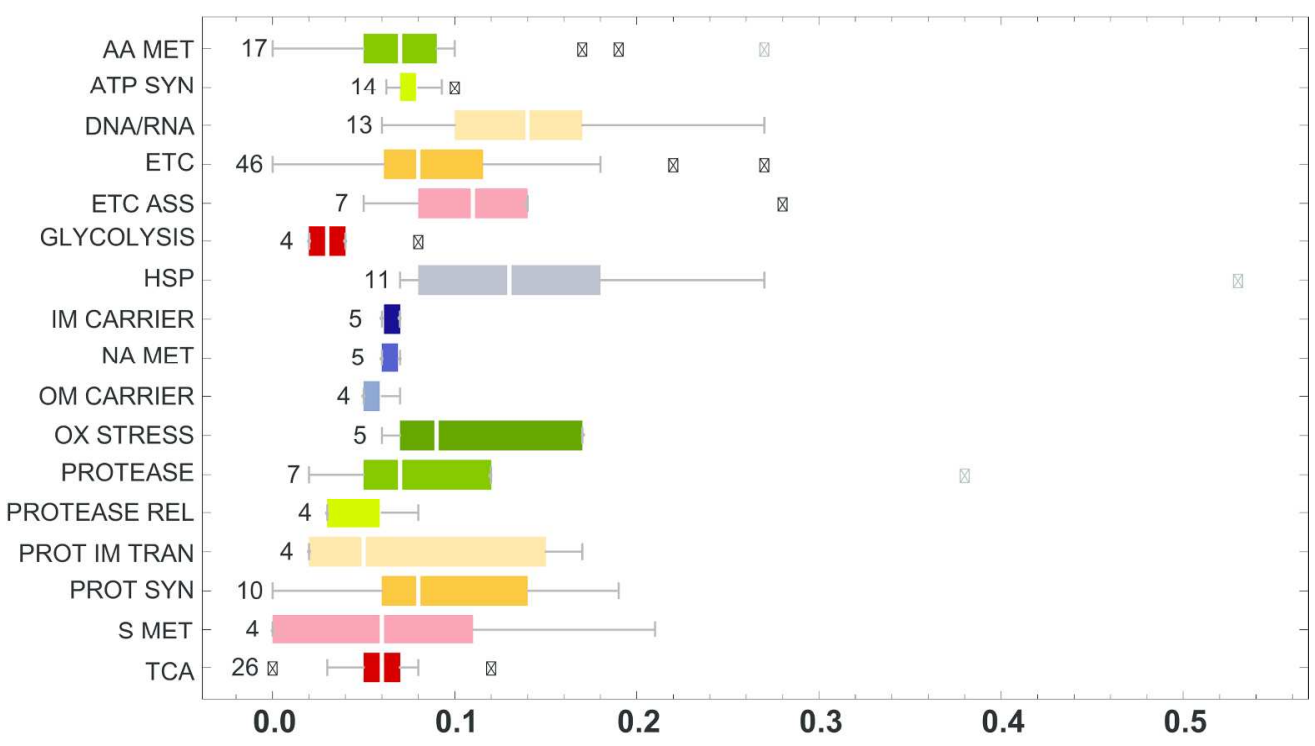

B.

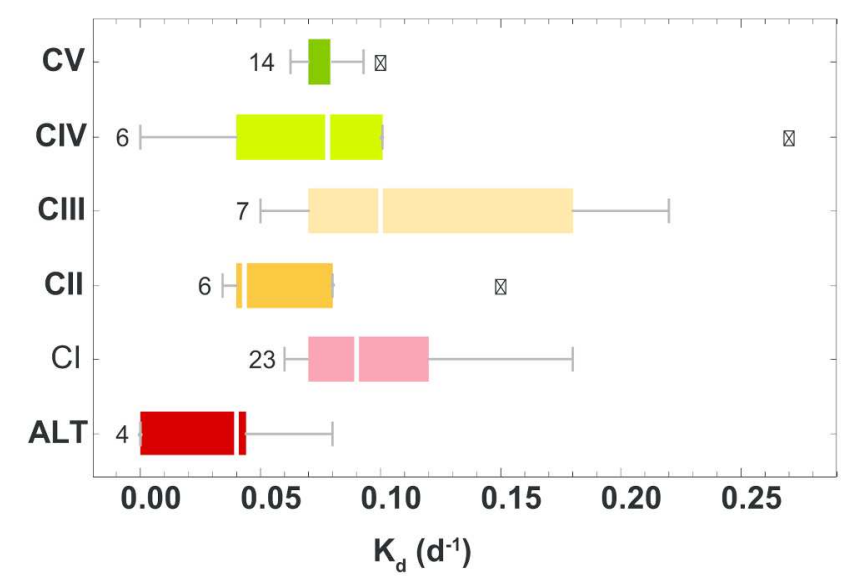

Figure 3 (A) Box and whisker plots of $\mathrm{Kd}$ values for mitochondrial proteins sorted by functional categorization, as assigned by the MapCave website (http://mapman.gabipd.org/web/guest/mapcave), with outliers represented by dots. Abbreviations: AA met, amino acid metabolism; ATP syn, ATP synthase DNA/RNA, DNA/RNA processes; ETC, electron transport chain; ETC ass, ETC assembly; HSP, heat shock proteins; IM carrier, inner membrane carrier; NA met, nucleic acid metabolism, OM carrier, outer membrane carrier; OX stress, oxidative stress; Protease rel, protease related; Prot IM tran, protein inner membrane transport; Prot syn, protein synthesis, S met, sulfur metabolism; TCA, tricarboxylic acid cycle. (B) Box and whisker plots of $\mathrm{Kd}$ values for mitochondrial respiratory complex subunits, with outliers indicated by dots. $205 \times 236 \mathrm{~mm}(300 \times 300$ DPI $)$ 
Figure 4 Color-coded image of Kd values for proteins of the mitochondrial Electron Transport Chain (ETC), as well as three other complexes: the FTSH protease complex, the prohibitin complex, and the VDAC import complex. Abbreviations: ETF, electron transfer flavoprotein; FTSH, filamentation temperature sensitive protease; PHB, prohibitin; VDAC, voltage-dependent anion channel. Subunits locations, shapes and abbreviations are based on models published before: CI 19, 48, 49, CII 50, CIII 51, CIV52, CV 18, EFT complex 53, 54, NDB55, FtsH and prohibitin complex 56. $297 \times 209 \mathrm{~mm}(300 \times 300$ DPI $)$ 

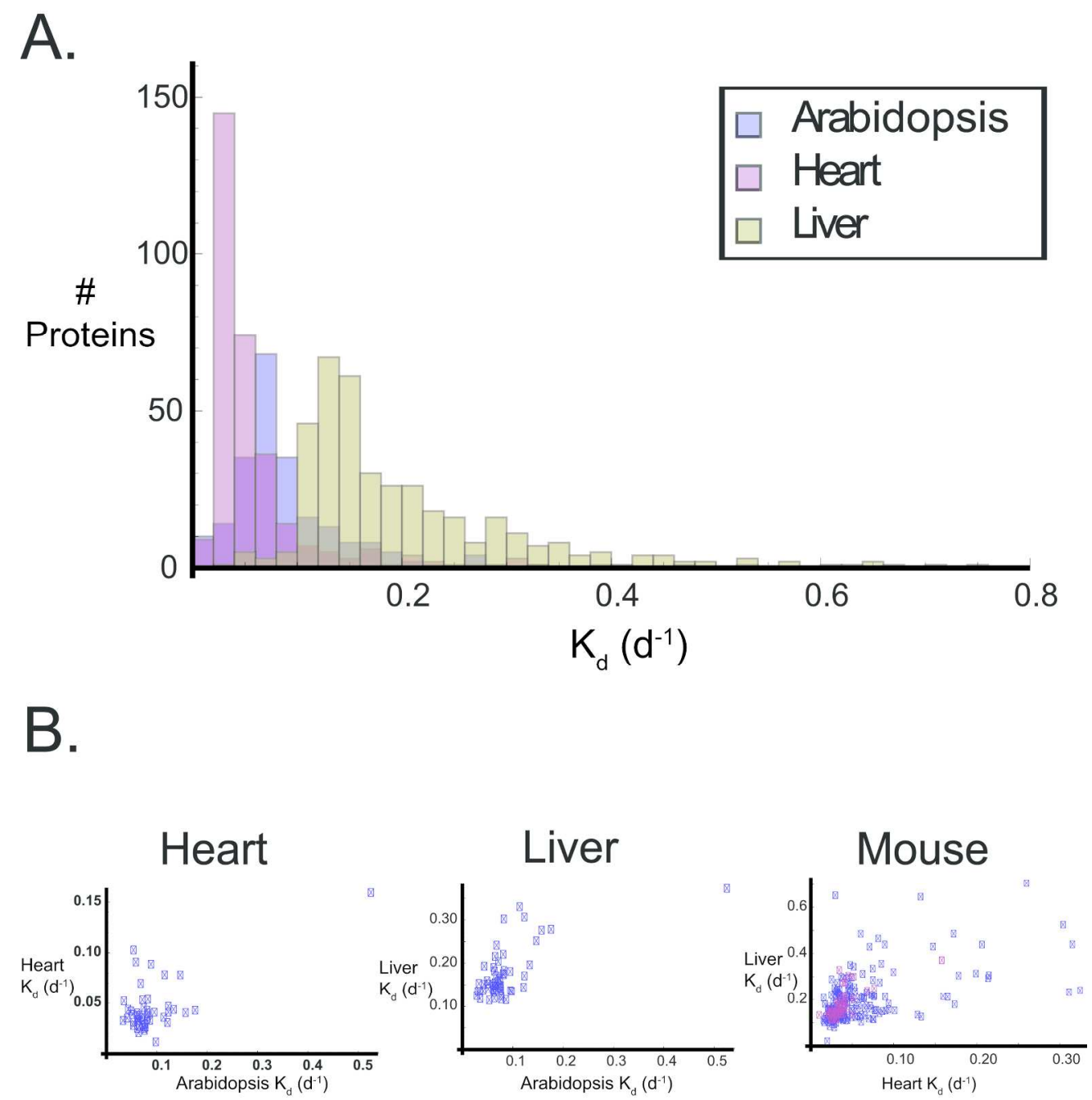

Figure 5 (A) Histogram of $\mathrm{Kd}$ values for Arabidopsis mitochondrial proteins and mitochondrial proteins derived from two different tissues of mouse, heart and liver 15. Marked in blue the Arabidopsis dataset, in purple the heart dataset and in brown the liver dataset. The three colors merge where datasets overlap. (B) Left, scatter plot of Kd values for mitochondrial proteins derived from mouse heart against $\mathrm{Kd}$ values for Arabidopsis mitochondrial proteins. Center, scatter plot of $\mathrm{Kd}$ values for mitochondrial proteins derived from mouse liver against Kd values for Arabidopsis mitochondrial proteins. Right, scatter plot of Kd values for mitochondrial proteins derived from mouse liver against $\mathrm{Kd}$ values for mitochondrial proteins derived from mouse heart. All mitochondrial proteins detected in the dataset are represented by blue squares, while the subset of mitochondrial proteins matched to Arabidopsis homologs detected in this study are marked by purple squares. $210 \times 216 \mathrm{~mm}(300 \times 300 \mathrm{DPI})$ 
Graphical Abstract Image 214x98mm (300 x 300 DPI)

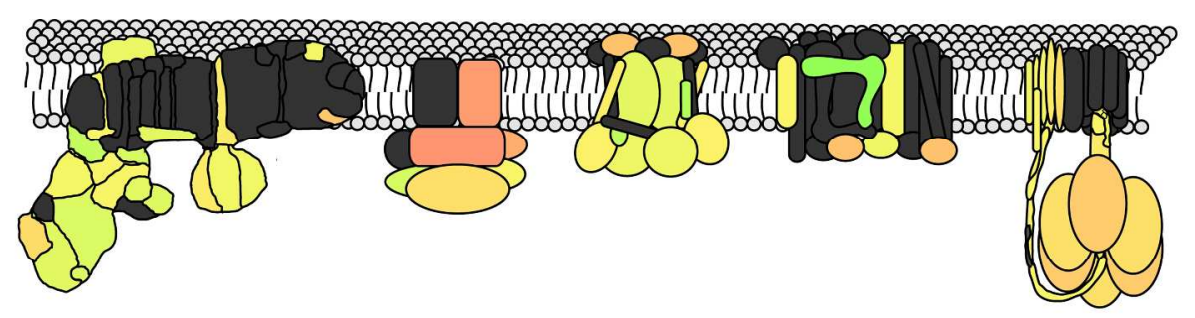

\section{Complex I Complex II Complex III Complex IV Complex V}

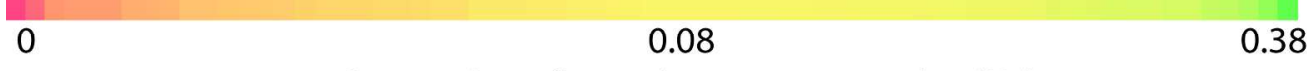

Proportion of protein turnover per day $\left(\mathrm{K}_{\mathrm{d}}\right)$ 